\title{
Macrophage-secreted Exosomes Delivering miRNA-21 Inhibitor can Regulate BGC-823 Cell Proliferation
}

\author{
Jian-Jun Wang ${ }^{1}$, Ze-You Wang ${ }^{2}$, Rui Chen ${ }^{3}$, Jing Xiong ${ }^{4}$, Yong-Liang Yao ${ }^{1}$, Jian- \\ Hong $\mathrm{Wu}^{1}$, Guang-Xin $\mathrm{Li}^{3 *}$
}

\begin{abstract}
Exosomes, membranous nanovesicles, naturally carry bio-macromolecules or miRNA and play impoetant roles in tumor pathogenesis. Here, we showed that macrophages cell-derived exosomes can function as vehicles to deliver exogenous miR-21 inhibitor into BGC-823 gastric cancer cells. Exosomes loaded with miR-21inhibitor significantly increased miR-21 levels in BGC-823, but miR-21inhibitor loaded in exosomes exerted an opposite effect. miRNA transfected with exosomes had less cellular toxicity to host cells compared to conventional transfection methods. The miR-21inhibitor loaded exosomes promoted the migration ability and reduced apoptosis of BGC-823 gastric cancer cells. These observations indicate that miR-21 acts as a tumor promoter by targeting the PDCD4 gene and preventing apoptosis of gastric cancer cells through inhibition of PDCD4 expression. Furthermore, exosome -mediated miR-21 inhibitor delivery resulted in functionally more efficient inhibition and less cellular toxicity compared to conventional transfection methods. Similar approaches could be useful in modification of target biomolecules in vitro and in vivo. These findings contribute to our understanding of the functions of miR-21 and exosomes as a carrier for therapy of gastric cancer.
\end{abstract}

Keywords: Exosomes - gastric cancer - miR-21 - macrophages

Asian Pac J Cancer Prev, 16 (10), 4203-4209

\section{Introduction}

Exosomes are small membranous vesicles generated by the inward budding of late endosomes, resulting in the formation of multivesicular bodies in the cytosol. They are subsequently exocytosed to the extracellular space by fusion with the plasma membrane (Vlassov et al., 2012). Exosomes are released by several cell types, including epithelial (Hu et al., 2013), dendritic (Segura et al., 2007), and tumor cells (Zech et al., 2012). Exosomes are also present in human body fluids such as amniotic fluid (Keller et al., 2011), urine (Chen et al., 2013), bronchoalveolar lavage fluid (Yamada et al., 2012), and malignant effusions (Torregrosa et al., 2012). It is possible that cell-derived vesicles such as exosomes could function as vectors for the intercellular transfer of molecules, thus providing a mechanism for cell-cell communication and the autologous amplification of cellular responses. Exosomes are involved in various pathologic conditions including tumorigenesis, establishing a pre-metastatic tumor niche, stimulating pathologic angiogenesis, promoting tumor immune escape by modulating $\mathrm{T}$ cell activities, and facilitating the spread of HIV (Izquierdo-Useros et al., 2010; Whiteside et al., 2011; Peinado et al., 2012; Ramakrishnaiah et al., 2012; $\mathrm{Mu}$ et al., 2013). Exosomes function in the transport and intercellular delivery of endogenous proteins and nucleic acids, and can also deliver exogenous pharmaceutical proteins and nucleic acids such as mRNAs, microRNAs (miRNAs) and siRNAs (Wahlgren et al., 2012; Chen et al., 2014). Exosome secretion of microvesicles transporting miRNAs, mRNAs, and proteins through bodily fluids facilitates intercellular communication and can elicit an immune response (McDonald et al., 2014).

MiRNAs are a class of 18-27-nucleotide singlestranded RNA molecules that bind to specific target mRNAs, leading to translational repression. Specific miRNAs function as negative or positive regulators of genes involved the development of tumor types (He et al., 2004; Bartel., 2009), such as lung cancer (Du et al., 2012), colorectal cancer (Menéndez et al., 2013), breast cancer (Liu., 2009), and gastric cancer (Wu et al., 2014). Gastric cancer is a major malignant tumor type, representing the second most common cancer and the leading cause of cancer mortality worldwide. This is especially the case in Asia, with the highest incidence being found in China, Japan, and Korea (Ferlay et al., 2010; Saeki et al., 2013), and about 1,000,000 new cases every year (Yang, 2006). There is increased expression of miR-421, miR-21, miR-221/222, and miR-106a in gastric cancer, while the expression of miR-124a, miR-

${ }^{1}$ Department of Clinical Laboratory, Kunshan First People's Hospital, Affiliated to JiangSu University, Kunshan, ${ }^{2}$ Department of Clinical Laboratory, The Second Xiangya Hospital of Central South University, ${ }^{4}$ Department of Ophthalmology, Xiangya Hospital, Central South University, Changsha, ${ }^{3}$ Department of Pathology, Chongqing Cancer Institute, Chongqing, China *For correspondence:lgxin34147@126.com 
Jianjun Wang et al

128b, miR-148, and miR-129 is reduced (Guo et al., 2009; Konishi et al., 2012). MiRNA-21 was one of the first miRNAs to be discovered in human cells, and its expression is significantly upregulated in different kinds of solid tumors, for instance breast and gastric cancer, and is closely associated with cancer pathogenesis (Huang et al., 2013). MiR-21 expression in gastric cancer tissues is significantly higher than in adjacent tissues. Moreover, gastric cancer patients have significantly altered levels of gastric juice miR-21 compared with patients with benign gastric diseases, indicating that miR-21 is a potentially useful biomarker for gastric cancer screening (Cui et al., 2013).

Elucidation of the specific mechanisms of miR-21 function in gastric cancer and exosome-mediated miRNA delivery may provide us with the knowledge to identify promising novel treatment strategies for gastric cancer.

\section{Materials and Methods}

\section{Cell culture}

U937 human acute monocytic leukemia and BGC823 human gastric cancer cells were purchased from the Center for Type Culture Collection of Wuhan University (Wuhan, China). U937 and BGC-823 cells were cultured in six-well plates or flasks at $37^{\circ} \mathrm{C}$ under $5 \% \mathrm{CO}_{2}$, in RPMI 1640-GlutaMAX medium containing $10 \%$ (v/v) fetal bovine serum (FBS), $100 \mathrm{U} / \mathrm{mL}$ penicillin, 0.1 $\mathrm{mg} / \mathrm{mL}$ streptomycin and $0.25 \mu \mathrm{g} / \mathrm{mL}$ amphotericin B. Differentiation of U937 cells into macrophage-like cells was induced by treatment with $0.1 \mathrm{mM}$ Phorbol 12-myristate 13-acetate (PMA) for $24 \mathrm{~h}$, which was purchased from Sigma Company (Missouri, USA) and dissolved in DMSO (Sigma, Missouri, USA), stored at $-20^{\circ} \mathrm{C}$, and used at a final concentration of $0.1 \mathrm{mM}$..

\section{Exosome purification}

U937 macrophage and BGC-823 cell culture supernatants were centrifuged at $3000 \times \mathrm{g}$ for $15 \mathrm{~min}$ to remove cells and cell debris, and transferred to sterile tubes. The appropriate ExoQuick Exosome Precipitation Solution (System Biosciences, San Francisco, USA) was added, and tubes were mixed by inverting and then refrigerated for $30 \mathrm{~min}$. The mixture was then sedimented at $1,500 \times \mathrm{g}$ for $30 \mathrm{~min}$, and the supernatant was removed by aspiration. Residual ExoQuick solution was removed by re-centrifugation at $1,500 \times \mathrm{g}$ for $5 \mathrm{~min}$ followed by aspiration. Finally, exosome pellets were resuspend in 1/10 original volume of nuclease-free water, $25 \mu \mathrm{L} 9 \%$ sucrose containing protease inhibitors (GenScript Biotechnology, Nanjing, China) was added, and the preparation was stored at $-4^{\circ} \mathrm{C}$. All procedures were carried out at $4^{\circ} \mathrm{C}$.

\section{Exosome identification by transmission electron microscopy \\ Freshly prepared exosomes were stained with 3\% phosphotungstic acid for $5 \mathrm{~min}$, placed on a copper grid, dried at $65^{\circ} \mathrm{C}$, and observed at $70,000 \times$ magnification using a Hitachi H-600 transmission electron microscope (Hitachi Manufacturing Corporation, Tokyo, Japan).}

\section{Cell transfection}

Exosomes were diluted 1:1 in Gene Pulser Electroporation buffer (Bio-Rad, California, USA). MiR21 inhibitor, miR-21 mimics, or negative control miRNA (Zimmer Pharmaceutical Biotechnology, Shanghai, China) was added to a final concentration of $150 \mathrm{pmol}$ to a $1 \mu \mathrm{g} / \mu \mathrm{L}$ exosome sample. The mixture was transferred to a $0.2 \mathrm{~cm}$ electroporation cuvette and electroporation was performed at $0.15 \mathrm{kV}$ and $100 \mu \mathrm{F}$. Finally, exosomes were treated with $1 \mathrm{U}$ RNase $\mathrm{H}$ to degrade miRNA outside the exosomes and then re-isolated using ExoQuick solution (System Biosciences, San Francisco, USA).

\section{Co-culture experiments}

Exosomes loaded with miR-21 inhibitor, miR21 mimics, or negative control miRNA (Zimmer Pharmaceutical Biotechnology, Shanghai, China) were cocultured with macrophages for $6 \mathrm{~h}$, followed by washing and medium replacement. The level of miR-21 was then assessed after $24 \mathrm{~h}$. U6 was used as internal control for RT-PCR analysis. For miR-21 inhibition, macrophages were seeded 1 day before treatment, and then subjected to different treatments for $24 \mathrm{~h}$. Treatments included miR-21 inhibitor-loaded exosomes, negative miRNAloaded exosomes, miR-21 mimic-loaded exosomes, miR-21 inhibitor plus ImagenFect RNAi transfection kit (Naomi Biotech, Wuxi, China), and miR-21 inhibitor plus X-tremeGENE HP RNAi transfection kit (Roche, Basel, Switzerland). The same miR-21 inhibitor concentration (300 pmol) was used for both exosome loading and chemical transfection methods. ImagenFect RNAi and X-tremeGENE HP RNAi transfection kits were used according to the manufacturer's recommendations. Relative miR-21 expression was measured by quantitative PCR (qPCR) using SYBR Premix ExTaq (TaKaRa Company, DaLian, China) according to the manufacturer's instructions. PCR cycling conditions were $95^{\circ} \mathrm{C}$ for 10 $\min , 95^{\circ} \mathrm{C}$ for $15 \mathrm{~s}$, and $60^{\circ} \mathrm{C}$ for $1 \mathrm{~min}$, for 30 cycles. Differences in relative expression between normal and pericarcinoma and gastric cancer tissues were calculated using the $2^{-\Delta \Delta \mathrm{Ct}}$ method, as follows: $\Delta \Delta \mathrm{Ct}=\Delta \mathrm{Ct}_{\text {reference }^{-}}$ $\Delta \mathrm{Ct}_{\text {sample }}$, where $\Delta \mathrm{Ct}$ is the difference in the cycling threshold between the gene of interest and the U6 "housekeeping" gene, $\Delta \mathrm{Ct}_{\text {sample }}$ is the $\mathrm{Ct}$ value for a given sample of pericarcinoma or gastric cancer normalized to the U6 gene, and $\Delta \mathrm{Ct}_{\text {reference }}$ is the $\mathrm{Ct}$ value corresponding to control samples normalized to U6 expression. Duplicate samples were run and mean $\mathrm{Ct}$ values were calculated.

\section{PCR analysis}

Total RNA was extracted using Trizol (TianGen Biotech, Beijing, China), according to the manufacturer's instructions. Reverse transcriptase reactions contained a 50 ng RNA sample $1 \mu \mathrm{L}, 0.5 \mu \mathrm{L}$ each forward and reverse primers, $4 \mu \mathrm{L} 1 \times \mathrm{RT}$ buffer (GenScript, Nanjing, China), 2 $\mu \mathrm{L} 0.25 \mathrm{mM}$ dNTPs, $0.5 \mu \mathrm{L} 3.33 \mathrm{U} / \mathrm{ml}$ MultiScibe reverse transcriptase (GenScript), and $0.5 \mu \mathrm{L} 0.25 \mathrm{U} / \mathrm{ml}$ RNase inhibitor (GenScript) and $11 \mu \mathrm{L}$ DEPC water. Reactions were incubated in an Eppendorf Realplex2 Detection System (Eppendorf, Germany) for $30 \mathrm{~min}$ at $16^{\circ} \mathrm{C}, 30$ 
$\min$ at $42^{\circ} \mathrm{C}$, and $5 \min$ at $85^{\circ} \mathrm{C}$, and then at a constant temperature of $4^{\circ} \mathrm{C}$. Reaction conditions for qPCR were 35 cycles of $95^{\circ} \mathrm{C}$ for $10 \mathrm{~min}, 95^{\circ} \mathrm{C}$ for $15 \mathrm{~s}$, and $60^{\circ} \mathrm{C}$ for $1 \mathrm{~min}$.

For RT-PCR, $20 \mu \mathrm{L}$ reactions containing $1 \mu \mathrm{L}$ cDNA, $0.5 \mu \mathrm{L}$ each forward and reverse primers, $2 \mu \mathrm{L} 2.5 \mathrm{mM}$ dNTPs (GenScript), $0.5 \mu \mathrm{L}$ DNA polymerase $(10 \mathrm{U} / \mu \mathrm{L})$ (GenScript Company, Nanjing, China), $4 \mu \mathrm{L} 1 \times$ buffer (GenScript) and $11.5 \mu \mathrm{L}$ DEPC water were subjected to 35 cycles of $95^{\circ} \mathrm{C}$ for $10 \mathrm{~min}, 95^{\circ} \mathrm{C}$ for $15 \mathrm{~s}$, and $60^{\circ} \mathrm{C}$ for $1 \mathrm{~min}$. PCR products were analyzed by $2.5 \%$ agarose gel electrophoresis. Specific primers were: miR-21 forward, 5' -ACGTTGTGTAGCTTATCAGACTG-3' , miR-21 reverse, 5' -AATGGTTGTTCTCCACACTCTC-3' ; U6 miR forward, 5' -ATTGGAACGATACAGAGAAGATT-3, U6 miR reverse 5' -GGAACGCTTC

ACGAATTTG-3'; miR-21 mimics, UAGCU UAUCAGACUGAUGUU and GA/AACAUCA GUCUGAUAAGCUAUU; miR-21 inhibitor, UCAACA UCAGUCUGAUAAGCUA; negative miRNA, AACC GGTTATCGACCGAACAAG.

\section{Western blotting analysis of PDCD4}

Proteins were extracted from BGC-823 cells transfected with various siRNA-loaded exosomes using a protein extraction kit (Tiangen Biotech, Beijing, China), and protein concentrations were measured by the Bradford method. Protein samples $(50 \mu \mathrm{g})$ were separated by $10 \%$ sodium dodecyl sulfate-polyacrylamide gel electrophoresis (SDS-PAGE) and transferred to polyvinylidene difluoride membranes (Millipore, Massachusetts, USA). Membranes were incubated with a rabbit anti-mouse PDCD4 antibody (Kuang Bo Biotechnology, Beijing, China), and then with an anti-rabbit horseradish peroxidase-labeled IgG secondary antibody.

\section{Cell migration and invasion assay}

Cell migration assays were performed using transwell chambers with $8 \mu \mathrm{m}$ pores (Chemicon, California, USA). Culture medium $(500 \mu \mathrm{L})$ containing $10 \%$ FBS (as a chemoattractant) was added to the lower chamber of each well. Cell suspension (106 cells, $300 \mu \mathrm{L})$ was added to the upper chamber and plates were incubated at $37^{\circ} \mathrm{C}$ for $24 \mathrm{~h}$. Cells that migrated to the lower surface of the polycarbonate membrane were stained with Giemsa solution and quantified by counting five randomly selected microscope fields at $40 \times$ magnification. Cell invasion assays were performed in a similar way using transwell chambers coated with Matrigel, and the number of cells that passed through the Matrigel matrix was determined after $24 \mathrm{~h}$.

\section{Flow cytometry analysis}

BGC-823 cells were transfected with exosomes loaded with various siRNAs, incubated for $24 \mathrm{~h}$, and then harvested and washed twice with PBS containing $0.2 \%$ BSA. Apoptosis was quantitatively determined in transfected BGC-823 cells by flow cytometry using an annexin V-FITC/PI apoptosis detection kit according to the manufacturer's instructions (BD, New Jersey, USA). Cell analysis and sorting were performed using a fluorescence-activated cell sorter (Beckman MOFLO XDP, California, USA).

\section{Statistical analysis}

Within each experiment, triplicates were performed for each condition or group. Data were analyzed using SPSS 16.0 (International Business Machines Corporation, New York, USA) and are presented as means \pm SEM of at least three independent experiments. Differences within each group were subjected to a t-test or q-test. Statistical significance was set at $\mathrm{P} \leq 0.05$ between groups (indicated by an asterisk).

\section{Results}

\section{Exosome morphology and composition}

Exosomes obtained from macrophages or BGC823 cells were observed by phosphotungstic staining and transmission electron microscopy. This revealed a homogenous population of morphologically typical vesicles 30-100 nm in diameter, as analyzed by NanoSight statistical software (Figure 1A-C). These were similar in appearance and size to those in published reports (Delcayre et al., 2006). Additionally, electrophoretic analysis showed that exosomes from both macrophages and BGC-823 cells contain proteins of many different sizes (Figure 1D), although there are clearly many different protein components in exosomes from macrophages (exo $\mathrm{M}$ ) and from BGC-823 cells (exo B).

Analysis of miR-421 levels and exosome-based delivery leads to minimal cytotoxicity

miR-21 expression in macrophage or BGC-823 cell exosomes and in whole cells was investigated by qPCR (Figure 2A). miR-21 mimics, miR-21 inhibitor, and negative miRNA were transported into BGC-823 cells by exosomes secreted from macrophages, and miR-21 levels in each experimental group were determined by

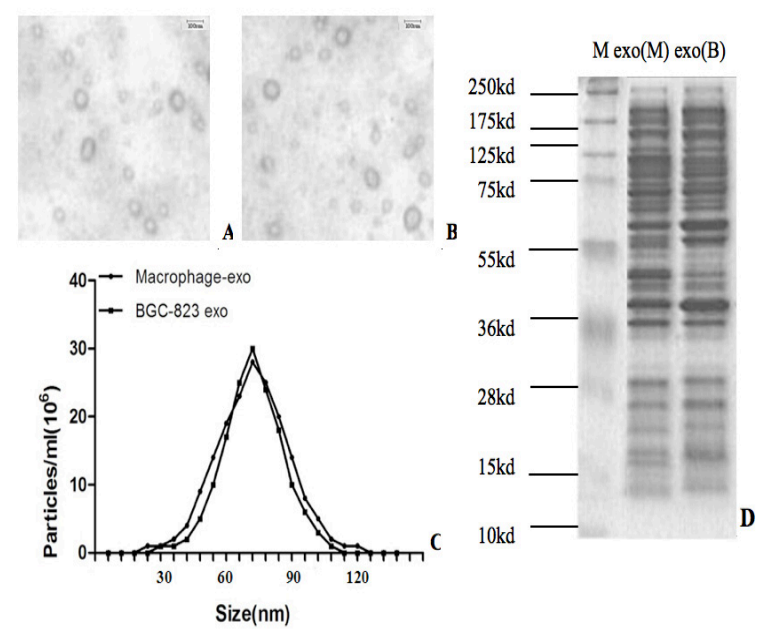

Figure 1. Analysis of Exosome Morphology and Composition. A or B: Exosomes were observed by transmission electron microscopy (magnification $\times 70,000$ ), scale bar: $100 \mathrm{~nm}$; C: The diameter of exosomes was determined using NanoSight statistical software. D: Protein expression in exosomes secreted from macrophages and BGC-823 cells was analyzed by $10 \%$ SDS-PAGE 

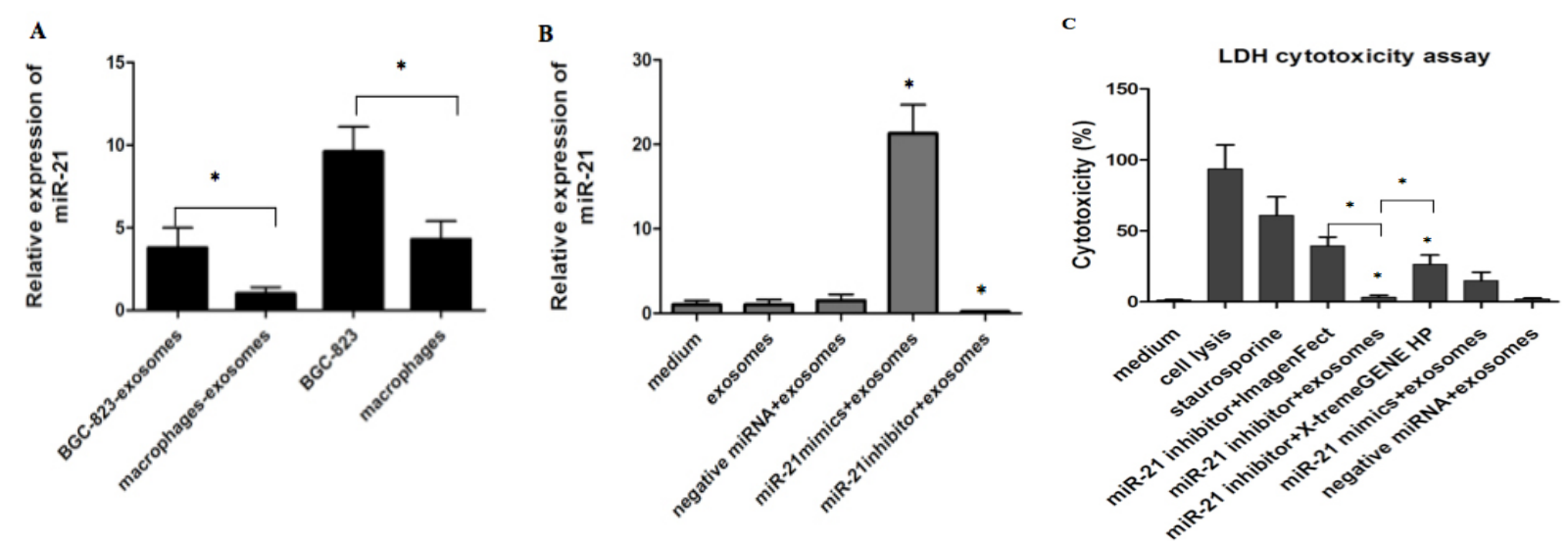

Figure 2. Analysis of miR-21 Levels in Exosomes, Exosome-secreting Cells, and Cells Transfected with siRNAloaded Exosomes. Meanwhile Cytotoxicity evaluation of exosomes-based miR-21 inhibitor delivery and conventional transfection reagents. A) MiR-21 expression in exosomes secreted from macrophages or BGC-823 cells was analyzed by qPCR. B) miR-21 levels in BGC-823 cells transfected with miR-21 mimics, miR-21 inhibitor, or negative miRNA loaded into exosomes secreted from macrophages. miR-21 levels were normalized to endogenous GAPDH (mean \pm SEM, three independent experiments). Statistical analysis was performed using SPSS $16.0, * P \leq 0.05$. C) After $24 \mathrm{~h}$ of co-culture, miR-21 inhibitor-loaded exosomes showed minimal toxicity, while miR-21 inhibitor plus ImagenFect or X-tremeGENE HP showed significant cytotoxicity $(* P<0.05)$. Statistical analysis was performed using SPSS 16.0, and all results represent three independent experiments

qPCR (Figure 2B). There was significantly less miR-21 in exosomes than in macrophages or BGC-823 cells. Importantly, the lowest miR-21 expression level was observed in exosomes secreted from macrophages. miR21 expression was lower in BGC-823 cells transfected with miR-21 inhibitor-loaded exosomes, but higher in BGC-823 cells treated with miR-21 mimic-loaded exosomes.

The cytotoxicity of conventional transfection reagents toward BGC-823 cells was analyzed by measuring lactate dehydrogenase (LDH) expression. The LDH level and percentage cytotoxicity were similar in BGC- 823 cells transfected with miR-21 inhibitor-loaded exosomes following transfection with two different reagents (ImagenFect and X-tremeGENE HP; Figure 2C). In all three experimental groups, LDH expression and percentage cytotoxicity increased significantly $(\mathrm{P}<0.05)$ after $24 \mathrm{~h}$.

\section{Analysis of PDCD4 expression}

BGC-823 cells were transfected with miR-21 mimics, miR-21 inhibitor, or negative siRNA loaded into exosomes and secreted from macrophages. Following this, a potential miR-21 target gene, programmed cell death protein 4 (PDCD4), and the encoded protein, which is thought to play an important role in apoptosis, were analyzed by RT-PCR and western blotting, respectively (Figure 3). Levels of PDCD4 gene and protein expression in BGC-823 cells were significantly increased following transfection with miR-21 inhibitor plus exosomes, but were significantly reduced following transfection with miR-21 mimics plus exosomes.

\section{Cell migration assay}

MiR-21 mimics, miR-21 inhibitor, or negative miRNA was transfected into BGC-823 cells via exosomes secreted from macrophages, and cells from the different experimental groups were incubated in transwell

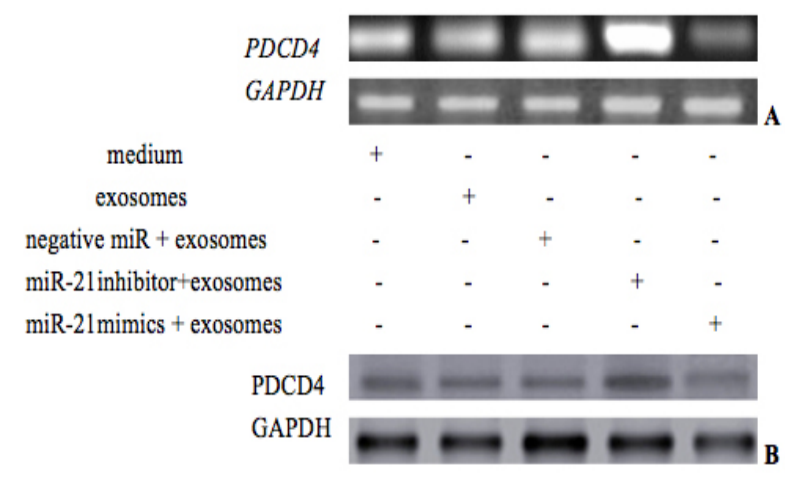

Figure 3. Analysis of PDCD4 Gene and Protein Levels in BGC-823 Cells Transfected with Various siRNAs Loaded into Exosomes. A) RT-PCR analysis of PDCD4 mRNA; B) Western blotting analysis of PDCD4 proteins. Data represent three independent experiments

chambers for $24 \mathrm{~h}$. Migrated cells were stained with Giemsa and observed by microscopy (Figure 4A). Cells of all four groups migrated through the membrane, but significantly fewer $(\mathrm{P}<0.05)$ cells transfected with miR21 inhibitor plus exosomes had migrated compared with all other groups. These date indicate that reduced miR-21 expression inhibits BGC-823 cell migration.

Changes that occur in the plasma membrane during apoptosis can be detected by annexin-V staining. We therefore measured apoptosis in siRNA-transfected BGC823 cells using annexin-V FITC and PI staining and flow cytometry (Figure 4C). BGC-823 cells transfected with miR-21 mimic-loaded exosomes had very low levels of apoptosis; in contrast, in BGC-823 cells transfected with miR-21 inhibitor-loaded exosomes there was a clear induction of apoptosis or necrosis. These results indicate that miR-21 may function as a tumor promoter in BGC823 gastric cancer cells. 


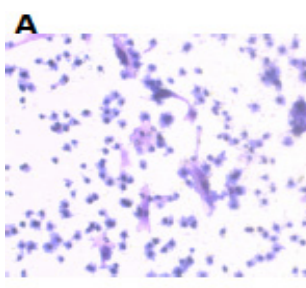

medium

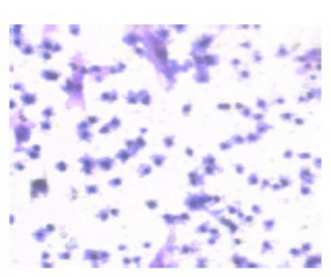

exosomes

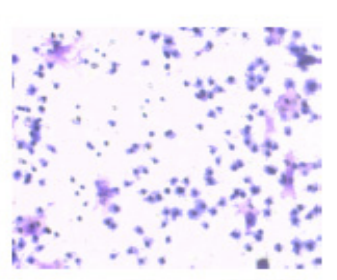

negative miRNA

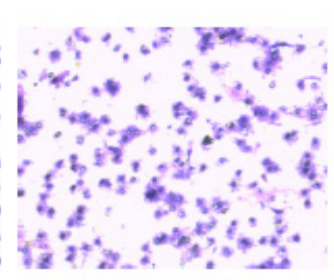

miR-21mimics

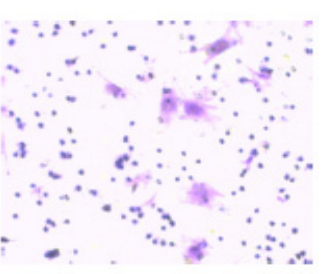

miR-21inhibitor

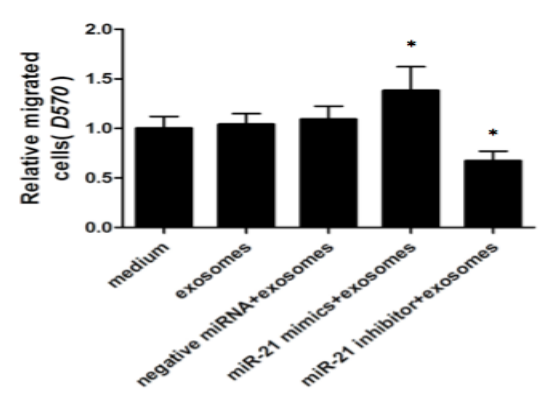

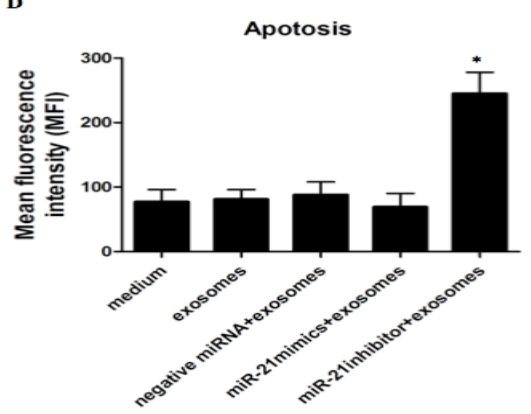

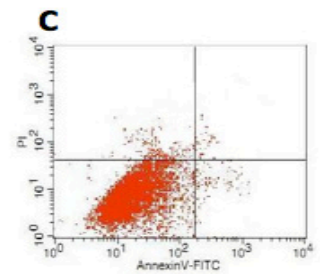

medium

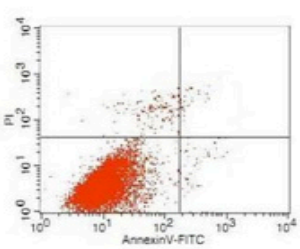

exosomes

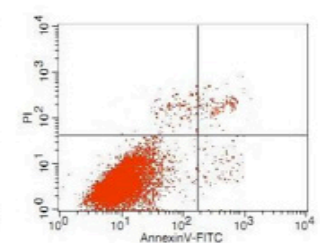

negative miRNA

+exosomes

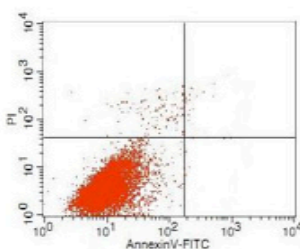

miR-21mimics

+exosomes

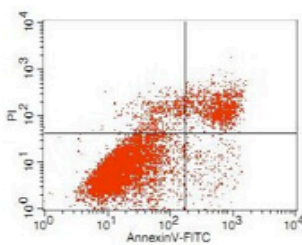

miR-21inhibitor

+exosomes

Figure 4. Analysis of the Migration Capacity of BGC-823 Cells Transfected siRNA Loaded Into Exosomes (magnification ×40), and flow Cytometric Determination of Apoptosis Levels in BGC-823 Cells Transfected with miR-21 mimics or miR-21 inhibitor Loaded Into Exosomes. A) Giemsa staining of migrated BGC-823 cells transfected with siRNA plus exosomes; B) D570 values were compared among different treated groups using SPSS16.0 statistical software $(* \mathrm{P}<0.05)$. Data represent three independent experiments. C) Flow cytometric analysis; D) Quantification of apoptosis and necrosis using SPSS 16.0. Data are presented as means $\pm \mathrm{SEM}(\mathrm{n}=3$ for three independent experiments $),{ }^{*} \mathrm{P}<0.035$

\section{Discussion}

Exosomes are natural nano-sized membranous vesicles and represent a hot topic in nanomedical research. As a consequence of their nanoscale size, their potential ability to express targeting ligands and deliver biomacromolecules, and their strong biocompatibility, exosomes are now emerging as attractive biological nanovesicle platforms for loading and carrying biomacromolecules for nanomedicine applications (Kooijmans et al., 2012; Zeng et al., 2002).

Exosomes secreted from most tumor cells, including breast cancer, gastric cancer, and lung cancer cells, contain a variety of miRNAs. MiRNAs are regulatory non-coding RNAs that control the activity of proteincoding genes by combining with the 3' UTR of target mRNAs and thereby inhibiting gene expression at the transcriptional or post-transcriptional level. They are involved in various processes from early developmental processes to cell differentiation and apoptosis. Multiple miRNAs associated with gastric carcinogenesis display tissue-specific expression, and can function as either tumor suppressors or oncogenes. A number of specific miRNAs are differentially expressed in gastric cancer and normal gastric mucosa: miR-21, miR-34b/c, and
miR-221/222 are upregulated gastric tumors, whereas miR-124a, miR-128b, and miR-148 are downregulated (Li et al., 2012; Hood et al., 2012). A clinical study found high miR-21 levels in exosomes from ovarian carcinoma effusion supernatants by qPCR, and these were associated with poor progression-free survival times (Vaksman et al., 2014). Additionally, human bronchial epithelial (HBE) cells release exosomes containing miR-21 that can stimulate proliferation in neighboring normal HBE cells. These data thus support the concept that exosomal miRNAs are involved in cell-cell communication during carcinogenesis induced by environmental chemicals (Xu et al., 2014). We found miR-21 to be expressed in U937 macrophages and BGC-823 cells, and in exosomes secreted from both cell types. However, expression levels were low in exosomes, especially in those secreted from macrophages, compared with expression in whole cells.

Exosomes have several characteristics that make them suitable nano-vehicles: they are small, relatively homogenous, and stable. Moreover, they can mediate gene delivery without inducing adverse immune reactions and pro-inflammatory responses (Alvarez-Erviti et al., 2011). Conversely, many of the frequently used gene therapy methods, including viral vectors, liposomes, and lipid nanoparticles that activate the host immune system, induce 
toxicity, and trigger inflammatory responses (Zhuang et al., 2011; Seow et al., 2009; Marcus et al., 2013). In this study, exosomes carrying a miR-21 inhibitor into BGC-823 cells had toxic effects on host cells, in contrast to the conventional ImagenFect and X-tremeGENE HP transfection reagents. Furthermore, miR-21 expression was significantly reduced in BGC-823 cells transfected with exosomes loaded with miR-21 inhibitor. In contrast, miR-21 expression was significantly increased in BGC-823 cells transfected with miR-21 mimic-loaded exosomes. These date suggest that exosomes represent a good system for carrying drugs into target cells to treat diseases.

Antisense inhibition of miR-21 in K562 cells suppressed cell migration, promoted cell apoptosis, inhibited cell growth, and upregulated the PDCD4 tumor suppressor gene. Additionally, treatment with pre-miRNA-21 increased cell migration and decreased apoptosis without affecting cell proliferation. These data suggest that miR-21 plays an oncogenic role in chronic myeloid leukemia (CML) and that antisense inhibition of miR-21 may therefore be therapeutically useful for CML (Hu et al., 2010). MiR-21 overexpression significantly enhanced proliferation or invasion and inhibited apoptosis in TPC-1 cells. Additionally, miR-21 may play an oncogenic role by directly targeting PDCD4 in the development of papillary thyroid carcinoma (PTC) ( Zhang et al., 2012). We transfected miR-21 inhibitor into BGC-823 cells via exosomes secreted from macrophages, and found a clear inhibition of cell migration and a remarkable increase in apoptosis.

In this study, our findings indicate that miR-21 upregulation in gastric cancer contributes to cell proliferation, thus suggesting that miR-21 may be a therapeutic target for gastric cancer. Additionally, exosomes secreted from macrophages may be efficient vehicles for RNA-based therapeutic strategies. We provided proof of concept for the use of exosomes as efficient delivery nano-vehicles with minimal cytotoxicity. We have therefore further elucidated the molecular mechanism associated with gastric cancer initiation and progression.

\section{Acknowledgements}

This work was supported by Science and Technology Project of Jiangsu Province in China (NO:KS1425). We thank Xiang Ya Hospital and Xiangya Medical college for technical assistance.

\section{References}

Alvarez-Erviti L, Seow Y, Yin H, et al (2011). Delivery of siRNA to the mouse brain by systemic injection of targeted exosomes. Nat Biotechnol, 29, 341-5.

Bartel DP (2009). MicroRNAs: Target recognition and regulatory functions. Cell, 136, 215-33.

Chen CY, Hogan MC, Ward CJ (2013). Purification of exosomelike vesicles from urine. Methods Enzymol, 524, 225-41.

Chen WX, Cai YQ, Lv MM, et al (2014). Exosomes from docetaxel-resistant breast cancer cells alter chemosensitivity by delivering microRNAs. Tumour Biol, 35, 9649-59.
Cui L, Zhang X, Ye G, et al (2013). Gastric juice MicroRNAs as potential biomarkers for the screening of gastric cancer. Cancer, 119, 1618-26.

Delcayre, A, L. Pecq, JB (2006). Exosomes as novel therapeutic nanodevices. Curr Opin Mol Ther, 8, 31-8.

Du L, Pertsemlidis A (2012). MicroRNA regulation of cell viability and drug sensitivity in lung cancer. Expert Opin Biol Ther, 12, 1221-39.

Ferlay J, Shin HR, Bray F, et al (2010). Estimates of worldwide burden of cancer in 2008: GLOBOCAN 2008. Int J Cancer, 127, 2893-917.

Guo J, Miao Y, Xiao B, et al (2009). Differential expression of microRNA species in human gastric cancer versus nontumorous tissues. J Gastroenterol Hepatol, 24, 652-7.

He L, Hannon GJ (2004). MicroRNAs: Small RNAs with a big role in gene regulation. Nat Rev Genet, 5, 522-31.

Hood JL, Wickline SA (2012). A systematic approach to exosome-based translational, nanomedicine. Wiley Interdiscip Rev Nanomed Nanobiotechnol, 4, 458-67.

Hu G, Gong AY, Roth AL, et al (2013). Release of luminal exosomes contributes to TLR4-mediated epithelial antimicrobial defense. PLoS Pathog, 9, 1003261.

$\mathrm{Hu} \mathrm{H,} \mathrm{Li} \mathrm{Y,} \mathrm{Gu} \mathrm{J,} \mathrm{et} \mathrm{al} \mathrm{(2010).} \mathrm{Antisense} \mathrm{oligonucleotide} \mathrm{against}$ miR-21 inhibits migration and induces apoptosis in leukemic K562 cells. Leuk Lymphoma, 51, 694-701.

Huang Y, Yang YB, Zhang XH, et al (2013). MicroRNA-21 gene and cancer. Med Oncol, 30, 376-8.

Izquierdo-Useros N, Naranjo-Gómez M, Erkizia I, et al (2010). HIV and mature dendritic cells: Trojan exosomes riding the Trojan horse? PLoS Pathog, 6, 1000740.

Keller S, Ridinger J, Rupp AK, et al (2011). Body fluid derived exosomes as a novel template for clinical diagnostics. $J$ Transl Med, 9, 86.

Konishi H, Ichikawa D, Komatsu S, et al (2012). Detection of gastric cancer-associated microRNAs on microRNA microarray comparing pre- and post-operative plasma. $\mathrm{Br}$ J Cancer, 106, 740-7.

Kooijmans SA, Vader P, van Dommelen SM, et al (2012). Exosome mimetics: a novel class of drug delivery systems. Int J Nanomedicine, 7, 1525-41.

Li SC, Liao YL, Ho MR, et al (2012). miRNA arm selection and isomiR distribution in gastric cancer. BMC Genomics, $\mathbf{1}, 13$.

Liu H (2012) MicroRNAs in breast cancer initiation and progression. Cell Mol Life Sci, 69, 3587-99.

Marcus ME, Leonard JN (2013). Fed exosomes: engineering therapeutic biological nanoparticles that truly deliver. Pharmaceuticals, 6, 659-80.

McDonald MK, Tian Y, Qureshi RA, et al (2014). Functional significance of macrophage-derived exosomes in inflammation and pain. Pain, 155, 1527-39.

Menéndez P, Villarejo P, Padilla D, et al (2013). Diagnostic and prognostic significance of serum microRNAs in colorectal cancer. J Surg Oncol, 107, 217-20.

Mu W, Rana S, Zöller M (2013). Host matrix modulation by tumor exosomespromotes motility and invasiveness. Neoplasia, 15, 875-87.

Peinado H, Alečković M, Lavotshkin S, et al (2012). Melanoma exosomes educate bone marrow progenitor cells toward a pro-metastatic phenotype through MET. Nat Med, 18, 883-91.

Ramakrishnaiah V, Thumann C, Fofana I, et al (2013). Exosomemediated transmission of hepatitis $\mathrm{C}$ virus between human hepatoma Huh7.5 cells. Proc Natl Acad Sci USA, 110, 13109-13.

Saeki N, Ono H, Sakamoto H, et al (2013). Genetic factors related to gastric cancer susceptibility identified using a genomewide association study. Cancer Sci, 104, 1-8. 
Segura E, Guérin C, Hogg N, et al (2007). CD8+ dendritic cells use LFA-1 to capture MHC-peptide complexes from exosomes in vivo. J Immunol, 179, 1489-96

Seow Y, Wood MJ (2009). Biological gene delivery vehicles: $d$. Mol Ther, 17, 767-77.

Torregrosa PP, Esser J, Admyre C, et al (2012). Bronchoalveolar lavage fluid exosomes contribute to cytokine and leukotriene production in allergic asthma. Allergy, 67, 911-9

Vaksman O, Tropé C, Davidson B, et al (2014). Exosomederived miRNAs and ovarian carcinoma progression. Carcinogenesis, 35, 2113-20.

Vlassov AV, Magdaleno S, Setterquist R, et al (2012). Exosomes: Current knowledge of their composition, biological functions, and diagnostic and therapeutic potentials. Biochim Biophys Acta, 1820, 940-8.

Wahlgren J, De L Karlson T, Brisslert M, et al (2012). Plasma exosomes can deliver exogenous short interfering RNA to monocytes and lymphocytes. Nucleic Acids Res, 40, 130.

Whiteside TL, Mandapathil M, Szczepanski M, et al (2011). Mechanisms of tumor escape from the immune system: adenosine-producing Treg, exosomes and tumor-associated TLRs. Bull Cancer, 98, 25-31.

Wu JH, Yao YL, Gu T, et al (2014). MiR-421 regulates the apoptosis of BGC-823 gastric cancer cells by targeting caspase-3. Asian Pac J Cancer Prev, 15, 5463-8.

Xu Y, Luo F, Liu Y, et al (2014). Exosomal miR-21 derived from arsenite-transformed human bronchial epithelial cells promotes cell proliferation associated with arsenite carcinogenesis. Arch Toxicol, [Epub ahead of print].

Yamada T, Inoshima Y, Matsuda T, et al (2012). Comparison of methods for isolating exosomes from bovine milk. $J$ Vet Med Sci,74, 1523-5.

Yang L (2006). Incidence and mortality of gastric cancer in China. World J Gastroenterol, 12, 17-20.

Zech D, Rana S, Büchler MW, et al (2012). Tumor-exosomes and leukocyte activation: an ambivalent crosstalk. Cell Commun Signal, 10, 37.

Zeng Y, Wagner EJ, Cullen BR (2002). Both natural and designed microRNAs can inhibit the expression of cognate mRNAs when expressed in human cells. Mol Cell, 9, 1327-33.

Zhang J, Yang Y, Liu Y,et al (20134). MicroRNA-21 regulates biological behaviors in papillary thyroid carcinoma by targeting programmed cell death 4. J Surg Res, 189, 68-74.

Zhuang X, Xiang X, Grizzle W, et al (2011). Treatment of brain inflammatory diseases by delivering exosome encapsulated anti-inflammatory drugs from the nasal region to the brain. Mol Ther, 19, 1769-79. 